\title{
Minimum and medium security
}

\author{
The interface: use of Section 17 trial leave
}

\author{
A. J. B. James, J. Smith, R. Hoogkamer, J. Laing and W. M. Donovan
}

\begin{abstract}
This paper examines the use of Section 17 trial leave from local poychiatilic units to regional secure units in order to focilliate the retum of patients to local services when higher secutty is no longer necessary. The current national shortage of medium secure beds is exacerbated by such patients when general poychiativic senvices are unwilling to have them back. Experience from the regional secure unlts in the old South Western Region hos shown beneficial effects of the use of Section 17 triat leave in this way.
\end{abstract}

Following the recommendation of the Report of the Committee on Mentally Abnormal Offenders (Butler Report; Home Office \& DHSS, 1975) and the Revised Report of the Working Party on Security in NHS Psychiatric Hospitals (Glancy Report; DHSS, 1974), regional secure units have been developed in all regions of England and Wales. These provide treatment in conditions of medium security for mentally disordered offenders and also for difficult to manage patients from local psychiatric units for a period of up to two years. The latter group poses major problems of ownership and can be rejected by the referring agencies as unplaceable.

Patients who are found to be unmanageable in open facilities or local intensive care units are often transferred to regional secure units. The majority of these patients are on treatment orders under Section 3 of the Mental Health Act 1983. The traditional method of transfer is under Section 19 of the Mental Health Act 1983. These patients are treated as if the application for admission for treatment were made to the receiving hospital. A consultant at the regional secure unit becomes the Responsible Medical Officer, and thus has statutory responsibilities under the Act. There is an expectation in most cases that once the patient's mental state and behaviour becomes sufficiently settled, the person will be returned to the local unit for further rehabilitation before discharge. This has not always worked to the satisfaction of Responsible Medical Officers or patients at regional secure units. Concerns have been expressed about the lack of facilities for those who move on from medium secure units and the unwillingness of local units to accept back patients transferred from local units to regional secure units who become 'forensic'. Medium secure units were set up to provide care for up to two years to prevent such units silting up with patients who had no discharge facility.

An alternative to full transfer under Section 19 is the provision under Section 17 of the Mental Health Act which allows the Responsible Medical Officer to grant any patient under his or her care leave of absence from the hospital. Leave of absence may be granted either indefinitely or on specified occasions (Section 17(2) ). The Responstble Medical Officer may revoke the leave of absence and recall the patient to the hospital. The patient remains liable to be detained under Section 3 or Section 37 for a period not exceeding six months from the first day of absence on leave. In order to extend the period of detention, the patient must be either returned to hospital or fully transferred to another hospital under Section 19. The practice of recalling a patient solely for the purpose of renewing the Order has been ruled illegal (Hallstrom, 1986). Under the terms of Section 17 leave, the patient remains the responsibility of the Responsible Medical Officer at the transferring hospital who is therefore responsible for consent to treatment and section renewal. The Managers under the Mental Health Act 1983 continue to be the Managers at the hospital of origin.

Section 17 leave has traditionally been granted from levels of high security to low security such as leave of absence for patients from special hospitals to regional secure units or local psychiatric hospitals. This aids quick recall to conditions of higher security should management be impossible in lower security.

The South Western Region has two reglonal secure units. The Butler Clinic which covers Devon and Cornwall is a $\mathbf{3 0}$ bedded facility which opened in 1983. The Fromeside Clinic covers the catchment area of Avon, Somerset and Gloucestershire. It also has 30 beds and opened in 1989. Both of these units use Section 17 to grant leave to patients detained at local psychiatric hospitals under Section 3 and 37 of the Mental Health Act when they are transferred to regional secure facilities. The rationale for the use of Section 17 
leave in this manner has been that the local consultant continues to have statutory responsibility for the care of the patient. The regional secure unit functions in this respect as a shortterm facility for assessment and acute crisis management. The local consultant continues to have responsibility for consent to treatment and reports to Managers and thus must take an active part in continuing patient care. The responsibility for appeals to Mental Health Review Tribunals remains with the local consultant. After the patient has been on leave for six months, a decision has to be made whether to implement a full transfer to the regional secure unit under Section 19, to discharge the patient or to recall the patient to the local unit. It has been the impression of those at regional secure units in the South Western Region that this has aided the return of patients from the regional secure unit to local hospitals when continued care at the regional secure unit is inappropriate and unnecessary.

Concern has been raised with regard to the use of Section 17 leave in this manner as applied in the South West. In the Fourth Biennial Report of the Mental Health Act Commission (1991), the Commission's view clearly stated that such a procedure is contrary to the intentions of Section 17, and that Section 19 transfers should be used in such cases. The main concerns were that after transfer occurs during an acute phase of mental disorder, that the patient is removed from easy access to his Responsible Medical Officer and Managers. The Commission accepted that the use of Section 17 in this way resulted from the reluctance of some district hospitals to accept the return of difficult patients once transfer out of their care had occurred.

In January 1993, the Department of Health issued guidelines in a letter on amendments to the Code of Practice - Mental Health Act 1983. In the proposed amendments the Department stated that the use of Section 17, to ensure that hospitals from which the patient had been granted leave will if necessary take the patient back in the future, is inappropriate and that transfer under the provisions of Section 19 should be used in its place. Objections to the proposed amendments were made by consultants in the South Western Region and it is interesting that these proposed amendments were not then found in the revised Code of Practice (Department of Health and Welsh Office. 1993).

In view of this controversy the authors commenced a review of the use of Section 17 trial leave during the ten years of its operation in the South Western Region, to try to ascertain whether the objectives inherent in its use are fulfilled.

\section{The study}

A retrospective case note review was conducted of all patients transferred from local hospitals to regional secure units in the South Western Region under Section 3/17 leave from 1983 onwards for the Butler Clinic and 1989 onwards for Fromeside Clinic.

\section{Findings}

In the ten years from September 1983 until August 1993 there were 78 Section 17 leaves from local units to the regional secure units involving 67 patients, amounting to $16.5 \%$ of all admissions. Two were admitted on three occasions and seven were admitted on two occasions. Fourteen patients were female and 53 male. The age range was from 18 to 65 with a mean of 30.3 years.

Assessment for admission was performed within two weeks on $93 \%$ of occasions with a median of four days. Most patients (90\%) were admitted within three weeks of assessment with a median of six days.

On average admissions lasted 113 days. The shortest stay was 14 days and the longest 477 . The most common reason for admission to the regional secure unit was an acute incident of aggression (37 cases; 47\%). Other causes were chronic behavioural problems ( 10 cases; $13 \%$ ), an acute incident of aggression accompanying a worsening psychosis (8 cases; 10\%), an acute incident of aggression and self-harming behaviour (5 cases: 6\%). Less frequent causes included absconding ( 4 cases; $5 \%$ ), acute on chronic behaviour problems ( 3 cases; $4 \%$ ) and self-harming behaviour ( 3 cases; $4 \%$ ), respite care, worsening psychosis alone and general assessment. The category of admission leading to the longest average length of stay was that of an acute incident of aggression accompanied by worsening psychosis and the second being an acute incident of aggression accompanied by chronic behavioural problems. The shortest length of stay was 14 days, involving a patient admitted for acute treatment of mania with associated aggressive behaviour.

The most common diagnoses were schizophrenia (30 patients; $38 \%$ ), manic-depressive psychosis (16 patients; $20 \%$ ) and personality disorder (11 patients; 14\%). Other diagnoses included schizoaffective disorder (7 patients; 9\%), substance abuse, Huntington's chorea, Asperger's syndrome and personality disorder with epilepsy.

The district making least use of the Section 17 arrangements was that which maintained a longstay difficult to manage locked facility. Other than this trend there is nothing notable in the use of the service over the years and no notable fluctuation in use could be attributed to the 
Table 1. Patients on Section 17 trial leave returned to local hospltals: month by month

\begin{tabular}{llllllll}
\hline Month number & 1 & 2 & 3 & 4 & 5 & 6 & $>6$ \\
\hline $\begin{array}{c}\text { Number of leave } \\
\text { patients returning } \\
\text { to local hospltals }\end{array}$ & 12 & 11 & 9 & 9 & 11 & 19 & 7 \\
\hline
\end{tabular}

closure of various long stay psychiatric hospitals within the region during the course of the study period. The use of Section 17 trial leave arrangements did not fluctuate markedly on a year by year basis throughout the ten years.

Of the total of 78 uses of trial leave, seven patients went on to be transferred under Section 19 at the end of the six month period. Table 1 shows the distribution of patients sent back to their local hospital on a month by month basis. A steady number of patients returned month by month to their hospital of origin for the first five months. During the sixth month, the time during which a decision needs to be made as to whether the patient should be fully transferred to the regional secure unit or the leave revoked and the patient returned to their hospital of origin, the numbers of transfers effectively doubled. Seven instances of transfer under Section 19 occurred. The seven occasions where transfer under Section 19 was brought about involved six patients, all having a diagnosis of schizophrenia or schizoaffective disorder.

\section{Comment}

The principal objective of the use of Section 17 trial leave in the South West has been to prevent patients remaining in unnecessarily restrictive care environments. Wood (1993) argues that it is a principle at the heart of the legal rules on mental lliness that patients should be constrained only as long or as much as is essential for their health and for the well-being of the community. According to Wood this requires an immediate transfer from levels of higher security to lower security. The Health Care Division of the Department of Health and the Mental Health Section of the Home Office have recently reiterated the endorsement given by ministers that a patient should be cared for under conditions of no greater security than is justified by the degree of danger they present to themselves or others (The Mental Health Foundation, 1993). In only seven instances of the 78 Section 17 transfers did patients remain in medium security beyond the six month period. This may, of course, be due to the general agreement that the patient needed to go back at that point and possibly would have happened without the use of Section 17 leave. It is interesting, however, that there was a significant increase in patients going back to their local unit during the sixth month. This seems to suggest that during this time there was a focusing of minds in making a decision as to whether someone was fit at that point to go back, or whether they needed to be fully transferred to the regional secure unit. The arrangement was flexdble enough on seven occasions to enable full transfer to take place. There was never a question of a patient presenting dangerous behaviour unmanageable in local units being sent back. It is certainly the recollection of the clinicians involved that the Section 17 trial leave arrangements had acted as a catalyst to patients going back to their local unit.

A control group of patients transferred from local facilities under Section 19 would have added weight to the findings but this has not been possible as all patients admitted from such facilities came on trial leave.

The authors contacted clinicians in several other regional secure units. None used Section 17 trial leave in this way and none were able to give detailed accounts of length of stay of those transferred from local units to the regional secure unit under Section 19 arrangements. It is therefore difficult to estimate how effectively the Section 17 arrangements prevented unnecessarily long stays at regional secure units. However, the authors would argue that Section 17 trial leave arrangements are in the interests: of the patient in avoiding inappropriately prolonged treatment in conditions of medium security; of the Service in that beds are freed up for new admissions; and of purchasers in that patients are not unnecessarily kept in expensive facilities.

Local clinicians and hospital managers have argued that the system is a heavy administrative burden and distances patients from their Responsible Medical Officer. None have so far refused to comply with the arrangement. The regional secure unit consultants argue that the benefits for patients who have a major interest in continued contact with local units and a swift return to them more than justifies the inconvenience.

It was interesting that the initial proposals by the Department of Health to amend the Code of Practice to outlaw the use of Section 17 in this way were evidently not included in the revised Code of Practice. The authors recommend that other regional secure units having difficulties outlined in this paper use Section 17 trial leave. Alternatively, further arrangements could be made using the Code of Practice or the Mental Health Act itself to ensure transfer of patients to less secure areas when the clinical need for high levels of security is removed. Section 17 helps to protect the civil liberties of patients. 
The use of Section 17 trial leave is not without its problems, in particular the clinical and administrattve burden on the local consultant and Managers who continue to perform tasks such as consent for treatment. This increased burden, however, ensures active interest on the part of local clinicians which the authors believe aids the liaison process and facilitates transfer back to conditions of lesser security.

\section{References}

DEPARTMENT OF HEALTH AND SOCIAL SECURTT (1974) Revised Report of the Working Party on Securtty in NHS Psychiatric Hospttals (Glancy Report. London: DHSS. DEPARTMENT OF HEALTH AND WELSH OFFICE (1993) Code of Practice. Mental Health Act 1983. London: HMSO. HALLSTROM, R. V. ex parte W (1986) AU ER 306.

HOME OFFICE \& DEPARTMENT OF HEALTH AND SOCINL SECURTY (1975) Report of the Committee on Mentally Abnormal Offenders (Butler Report). (Cmnd 6244). London: HMSO.

MENTAl HEAlth ACt COMMISsion (1991) Fourth Biennial Report 1989-1991. London: HMSO.
Mental Health Foundation (1993) Diversion, Care and Justice. London: The Mental Health Foundation.

WoOD, J. (1993) Future directions for mental health law. In The Mentally Disordered Offender in an Era of Community Care: New Directlons in Proulsion leds W. Watson \& A. Grounds). Cambridge: Cambridge Untversity Press.

*Adrian James, Consultant Forensic Psychiatrist, Langdon Hospital, Exeter Road, Dawlish, Devon EX7 ONR; Jeanette Smith, Consultant Forensic Psychiatrist, Fromeside Clinic, Blackberry Hill, Bristol BS16 1ED; Rini Hoogkamer, Senior House Officer in Forensic Psychiatry: Jeremy Laing, Senior House Officer in Forensic Psychiatry; and Martin Donovan, Consultant Forensic Psychiatrist, Langdon Hospital, Exeter Road, Dawlish, Devon EX7 ONR

*Correspondence

\title{
Management of Violence and Aggression in Health Care
}

\author{
Edited by Brian Kidd and Cameron Stark
}

A multidisciplinary approach to the management of violence, bringing together expert knowledge from medical, nursing, social work and other professionals

$\square$ Describes ways of assuaging violence both practically and with the use of medication

Discusses the role of the organisation and ethical considerations

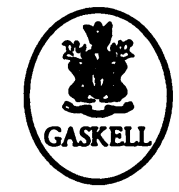

- £12.50 200pp. ๑ $1995 \bullet$ ISBN 0902241842

Available from bookshops and from the Publications

Department, Royal College of Psychiatrists, 17 Belgrave Square,

London SW1X 8PG (Tel. 0171-235 2351 extension 146) 